\title{
Deconstructing the ivory tower: identifying challenges of university-industry ecosystem partnerships
}

\author{
Emily C. Bacon ${ }^{1}$ (D) Michael D. Williams ${ }^{1}$ (D)
}

Received: 31 March 2020 / Accepted: 29 December 2020 / Published online: 27 January 2021

(c) The Author(s) 2021

\begin{abstract}
Collaboration between industry and academia necessitates the management of entrepreneurial dynamics within ecosystem contexts. However, such partnerships perpetuate numerous challenges that, without effective management, can impact upon the ecosystem as a whole. Limited research to date has addressed the challenges affecting these university-industry partnerships and ascertained their impact upon ecosystem management. This study identifies the challenges pervading universityindustry partnerships across entrepreneurial ecosystems, with a view that through an exposition of such challenges, more specific strategies could be implemented to address them. Questionnaires were distributed to key ecosystem stakeholders, requesting their perceptions of the key challenges affecting their collaborative relationships. Empirical data was analysed utilising fuzzy-set qualitative comparative analysis to deduce the configurational nature of the conditions. Results reveal mutually exclusive solutions grounded upon distinct combinations of conditions, constituting distinct pathways to ineffective ecosystem management. Theoretical and practical implications are discussed, as well as acknowledged limitations of this study and suggestions for future research.
\end{abstract}

Keywords Entrepreneurial · Ecosystem · University-industry · FsQCA

JEL Classification M0

\section{Introduction}

The general broadness and multidisciplinarity of the ecosystem construct can be attributed to its widespread application in business and management, both theoretically and practically (Autio et al. 2018). While relevant across multiple fields, the concept of the ecosystem retains a significant relation with the field of

Emily C. Bacon

e.c.bacon@swansea.ac.uk

1 School of Management, Swansea University, Bay Campus, Swansea SA1 8EN, UK 
entrepreneurship (Audretsch and Belitski 2016). In line with the ecosystem analogy, Moore (1993) argues that while ecological elements rely upon each other in a biological ecosystem, entrepreneurial ecosystems are formulated of numerous stakeholders, coordinating and coevolving their capabilities around a new innovation. Entrepreneurial ecosystems encompass an emergent research field (Hakala et al. 2019) that is progressing rapidly (Kang et al. 2019) and gaining increasing importance in high-tech industries where open innovation commonly occurs between partners (Kraus et al. 2018a, b). Consequently, entrepreneurship literature demonstrates a growing interest in innovation-related ventures rather than more traditional measures of entrepreneurship (Cavallo et al. 2018). Ultimately, research argues that innovation systems such as ecosystems fail to exist without the presence of entrepreneurs (Hekkert et al. 2007). Hence, with extant literature emphasising a strong interrelation between innovation and entrepreneurship (Bosco et al. 2018; Ferreira et al. 2017; Roig-Tierno et al. 2018) the innovation partnerships occurring within entrepreneurial ecosystems constitute an important research area.

Ecosystems encourage institutions to interact, communicate, transfer knowledge and be creative (Bouncken et al. 2018). Industry 4.0 has stimulated a wide variety of firms to engage in entrepreneurial ecosystems (Schneider 2018) including large firms, universities, financial firms, and public organisations that support new and growing firms (Brown and Mason 2017). The diverse nature of these partners hence necessitates the investigation of the entrepreneurial ecosystem across different contexts (Autio et al. 2014). Universities adopt several roles within an ecosystem (Malecki 2018). University-industry partnerships involve collaboration between academic institutions and non-academic organisations (see Perkmann and Walsh 2007 for a more detailed exploration). Rising university-industry collaboration has led to increased innovation activity (Perkmann and Walsh 2007) which can lead to commercialisation through the creation of new ventures (Bosco et al. 2018). Theoretically this process is coined 'academic entrepreneurship' and comprises a burgeoning research avenue, with recent studies attempting to shed light on the conditions and factors that favour or inhibit this phenomenon (Bosco et al. 2018). However, universities can also collaborate with industry for alternative purposes. Research organisations such as universities may be at a position to provide novel knowledge formulated upon emerging research ideas (Nieto and Santamaría 2007). Universitybased research operates as a significant knowledge asset, facilitating more effective knowledge searches by firm researchers for the purposes of innovative developments (Chesbrough et al. 2006). Reflecting the premise of open innovation, Ivascu et al. (2016) argue that universities assist organisations in researching potential issues that cannot be solved by the organisation itself.

The significance of university-industry knowledge sharing has become increasingly necessary in recent years (Carayannis et al. 2019). Such partnership types enable firms to access differentiated knowledge (Santoro and Saparito 2006). Universities support innovation in general (Arant et al. 2019) operating as a source of new ideas, with industry offering pathways to capitalise upon such ideas (Ferreira and Carayannis 2019; Wit-de Vries et al. 2019). The multi-disciplinary research arising from university-industry partnerships is vital for solving increasingly complex social problems (Boardman and Gray 2010). Hence, university-industry partnerships 
generate intangible support infrastructures and drive innovation, growth and prosperity in the wider economy. However, the circumstances under which such university-industry collaboration is successful remains unclear (Arant et al. 2019). Hence, in order to increase the likelihood of successful collaboration, key challenges need to be addressed (Bruneel et al. 2010).

Given the interrelation between universities and industry (Erina et al. 2017) existing debates focus on how entrepreneurial dynamics are governed, and which actors, such as universities, play a significant role (Cavallo et al. 2018). Resultantly, Cavallo et al.(2018) call for a common perspective on the governance mechanisms that regulate the evolutionary process of entrepreneurial ecosystems. While some studies have explored the key challenges facing entrepreneurial ecosystems (Autio and Levie 2017) explicit attention towards the dynamic challenges between universities and industry collaboration remains largely absent from extant entrepreneurial ecosystems literature. Consequently, Vasconcelos et al. ( 2018) call for further research on how to effectively manage challenges across an ecosystem. Correspondingly, building upon the research of Bosco et al. (2018), who identify key challenges of the academic entrepreneurial process, this study ascertains the challenges of the relationships between industry and academia within entrepreneurial ecosystems. Moreover, identifying how these challenges contribute to ineffective management is key. Given that extant literature cites a multitude of challenges (see Sect. 2) it becomes unlikely that a single challenge pervades all partnerships; indeed, in a practical sense, partnership issues rarely originate from a single factor. They are more likely to originate from a complex myriad of conditions, thus making fsQCA an apt analytical tool for analysing the combinations of conditions that lead to ineffective ecosystem management. Due to the significant relationship between university and industry in ecosystem contexts (Malecki 2018) identifying how these partnerships are managed and what barriers need to be overcome to ensure effective management becomes crucial and remains an area of research that is largely absent from extant ecosystems literature.

This study remedies this absence by making the following contributions. Firstly, ecosystem partnerships often exhibit high failure rates (Lauritzen and Karafyllia 2019). This study offers a novel contribution to the entrepreneurial ecosystems literature through identifying the conditions that lead to ineffective ecosystem management. This leads to potential explanations of why ecosystem partnerships fail, an important implication for practitioners who could resultantly attribute partnership failure to specific factors that may exist in their partnerships. Second, while research has begun to provide greater insights into the key challenges affecting entrepreneurial ecosystems (Bosco et al. 2018) further work is needed to ascertain the configurational nature of these conditions. This study extends previous research examining different ecosystems through an entrepreneurial lens (Theodoraki and Messeghem 2017) utilising fsQCA to detect how conditions combine into configurational recipes, revealing that all conditions are sufficient for ineffective ecosystem management, but not necessary. This study hence contributes to the ecosystems literature through evidencing the interconnected causal relations between the conditions, and their combinations into multiple solutions, which further elucidates how ineffective ecosystem management occurs. This offers important insights for 
practitioners, revealing that often, ineffective ecosystem management does not arise due to independent, isolated factors posing a challenge, but instead multiple conditions that occupy core and peripheral positions. In addition, with extant entrepreneurial ecosystems research primarily conducted in the US (Kang et al. 2019; Liguori et al. 2019) this study offers a geographically distinct analysis through utilising a UK-based sample. Finally, with existing studies demonstrating a preference towards comparative methodologies (Arruda et al. 2014; Manolova et al. 2017; Voelker 2012) this study utilises fuzzy-set Qualitative Comparative Analysis (fsQCA) to identify causal configurations of key challenges that contribute to ineffective ecosystem management, contributing to the rising application of configurational techniques in innovation-related disciplines (Kraus et al. 2018a, b) and entrepreneurship (Zardini et al. 2020). Identifying the interrelations between ecosystem challenges can assist practitioners in recognising the patterns of conditions that contribute to ineffective ecosystem management, facilitating an increased understanding of how to better manage their ecosystem partnerships.

The remainder of this paper is structured as follows. Section 2 outlines the research literature pertaining to university-industry partnerships across entrepreneurial ecosystems. Section 3 presents the methodology for this study. Results arising from fsQCA are provided in Sect. 4, with a discussion explored in Sect. 5. Finally, key conclusions, alongside theoretical and practical implications, and limitations of this research are provided in Sect. 6.

\section{Literature review}

\subsection{University-industry links in entrepreneurial ecosystems}

We conducted a narrative review of the ecosystem literature to provide a general discussion of university-industry partnerships in ecosystem contexts. Utilising major research databases such as EBSCO, Scopus, Emerald, and Web of Science, key terminology such as 'entrepreneurial ecosystem' and 'university-industry' was inputted into the search engines.

Entrepreneurial ecosystems emphasise interdependence between actors and factors, viewing entrepreneurship as an output of the ecosystem (Acs et al. 2017). Universities significantly contribute to entrepreneurship (Breznitz and Zhang 2019). Existing research has utilised case studies to explore how universities have established entrepreneurial ecosystems, such as highlighting the ways in which academics engage in the entrepreneurship process (Lahikainen et al. 2019) exploring the role of technology transfer offices in developing an entrepreneurial ecosystem (Schaeffer and Matt 2016) or elucidating how campuses operate as ecosystems themselves (Miller and Acs 2017). Breznitz and Zhang (2019) further elucidate the role of the university in the entrepreneurial ecosystem through examining how a university operates as an accelerator for student start-ups. Brito (2018) applied a case study methodology to examine the central role of universities within their innovation ecosystem, finding that universities act as leaders and integrators. Measuring the converse relationship, Nicholls-Nixon et al. (2020) explore the role of the 
entrepreneurial ecosystem in shaping the development of university-based incubators. Hayter (2016) finds that social networks of faculty and graduate entrepreneurs drive the growth of university entrepreneurial ecosystems. Meng et al. (2019) evidence how knowledge transfer from the direction of university to industry evolves across different phases of academic entrepreneurship within an ecosystem.

While universities can collaborate with industry to form entrepreneurial ecosystems, such partnerships can also be present in wider ecosystem infrastructures, such as quadruple-helix ecosystems (Carayannis and Campbell 2009). In exploration of the knowledge transfer process, Miller et al. (2016) studied knowledge transfer factors across quadruple helix ecosystems, applying an absorptive-capacity lens: they found factors affect both the effectiveness and ability of stakeholders to engage in knowledge transfer. Bacon et al. (2019a, b) examine university-industry knowledge transfer enablers, confirming their configurational nature for a successful transfer process.

\subsection{Ecosystem challenges}

While these preliminary insights provide important implications for universityindustry ecosystem partnerships, limited research has explored the challenges pervading these relationships in ecosystem contexts, and how they are overcome (Al-Tabbaa and Ankrah 2016). Entrepreneurs are faced with the challenge of coordinating networks of actors for numerous developments that occur in the presence of multiple uncertainties (Vasconcelos et al. 2018). As ecosystems rely upon multiple people, processes, and tools in order to operate effectively, it is perhaps unsurprising that multiple challenges can arise. Hakala et al. (2019) argue that these elements are less effective as economic agents when operating in isolation: the interaction between them determines the success of the ecosystem. Lakitan (2013) stresses that university-industry partnerships can experience numerous challenges, including low technological demand, unintensive communication, and limited adoption of innovations. Moreover, Lakitan (2013) argues that for university-industry ecosystem partnerships, 'Ivory Tower Syndrome' can still present an issue, whereby potential partners are discouraged from initiating a partnership due to universities being disconnected from everyday norms and practices. When engaging in new ventures, Lubik et al. (2013) state ecosystems are faced with numerous challenges including that the need for process innovations, need for complementary innovations, resource demands and long development times require managing complex constellations of actors to achieve successful commercialization. The impact of these challenges on effective ecosystem management becomes greater when removing them relies upon individual as well as collective efforts (West 2014). 


\section{Research propositions}

Existing literature cites a multitude of challenges as affecting university-industry partnerships, including firm innovativeness (Howells et al. 2012; Laursen and Salter 2004) partnership expectations (Cheng and Fu 2013; Santoro and Saparito 2006; Steinmo and Rasmussen 2018) and relational risk (Fulop and Couchman 2006; Perkmann et al. 2011; Radziwon and Bogers 2019). Limited empirical research explores these challenges in the context of university-industry ecosystem partnerships and analyses how different configurations of these challenges may impact upon ecosystem management. Thus, to contribute towards a more coherent understanding of the configurational nature of these conditions, this study employs fsQCA to identify the complex causal interrelations between the conditions.

FsQCA is grounded upon the notion of equifinality, which purports that multiple, mutually exclusive solutions are likely to contribute to an outcome (Fiss 2011). Given that multiple conditions are cited within the extant research literature, it is unlikely that a single condition will retain overall responsibility for contributing to ineffective ecosystem management. Conditions are hence likely to combine configurationally as a component of any solution, constituting distinct pathways to ineffective ecosystem management. Thus, the following propositions are outlined:

Proposition 1 Multiple, mutually exclusive solutions contribute to ineffective ecosystem management.

Proposition 2 No single condition retains overall responsibility for ineffective ecosystem management.

\subsection{Methods}

\subsubsection{Procedure and subjects}

An initial background study was conducted to identify the key challenges pervading ecosystem partnerships. Ten individuals representing university-industry collaboration were interviewed using a semi-structured approach and were asked to discuss the challenges that commonly arose within their ecosystem partnership. Interviews were recorded and transcribed, and analysed thematically.

Based upon the challenges identified in the background study, and to confirm whether such challenges were prevalent within existing university-industry ecosystem partnerships, a questionnaire was administered to key ecosystem stakeholders. To enable compatibility with fsQCA, the questionnaires required participants to assess the extent of their agreement on a seven-point Likert scale. Statements relating to each condition were included to ascertain whether participants viewed these conditions as presenting a challenge to effective ecosystem management. For example, for mistrust, participants were asked "To what extent do you agree/disagree that a lack of trust presents a challenge to ecosystem management?" These questions 
were then supplemented with additional questions encouraging participants to provide a rationale for their response, akin to Bacon et al.'s (2019a, b) study, in order to enable participants to expand upon their answers if they so wished.

As fsQCA requires an outcome measure, this study examined the extent to which the six conditions contributed to effective ecosystem management. Building upon the definition outlined by Moore (1996), this study views effective ecosystem management according to the presence of the following five components: (1) the ecosystem is effective in managing co-evolving, symbiotic, and self-reinforcing strategic contributions; (2) the ecosystem is invested in by members of the community; (3) the ecosystem progresses on the creation of end-to-end experiences of value to customers; (4) the ecosystem implements community-level governance; and (5) the ecosystem is aligned around shared intentions and a shared vision of the ecosystem future. To incorporate this measure within the questionnaires, five separate Likertscales corresponding to each component were included. These five aspects are associated with effective ecosystem management: however, this study is investigating the extent to which the challenges contribute to ineffective ecosystem management, and hence the conditions were measured against the absence of this outcome (see Sect. 3.3).

The questionnaire was pre-tested on a sample of five participants, comprised of lay individuals who had no prior experience of ecosystem involvement, but held professional occupations. Minor revisions relating to the clarity of the questionnaire were made, with the questionnaire subsequently being distributed through online platforms. Contacts obtained through the authors' networks were invited to participate in the questionnaire, to discuss their perceptions of their university-industry partnerships residing within their ecosystem. To ascertain whether the challenges were present within existing university-industry ecosystem partnerships, participants with a wealth of experience engaging in entrepreneurial ecosystems were purposively sought. Snowball sampling was utilised to identify potentially suitable contacts who then provided details of further contacts. Participants were purposively sought according to their aptitude and experience in innovation ecosystem management: such participants were asked to provide contact details of other potentially suitable participants. Such participants were then invited to participate via email. A total of 19 complete responses were returned. Participants were either university or industry representatives, and all participants were based in the UK. Table 1 displays participant demographics.

\subsection{Rationale and strengths of fsQCA}

FsQCA bridges the divide between qualitative and quantitative methods. It retains some fundamental strengths of the qualitative, case-oriented approach through adopting of a view of the case as a holistic entity (Rihoux and Lobe 2009); as such, the essence of the case is not lost within the analysis, as all its interrelated components are wholly considered. Alternatively, fsQCA also implements some fundamental characteristics of quantitative approaches to data analysis. Primarily, it enables a 


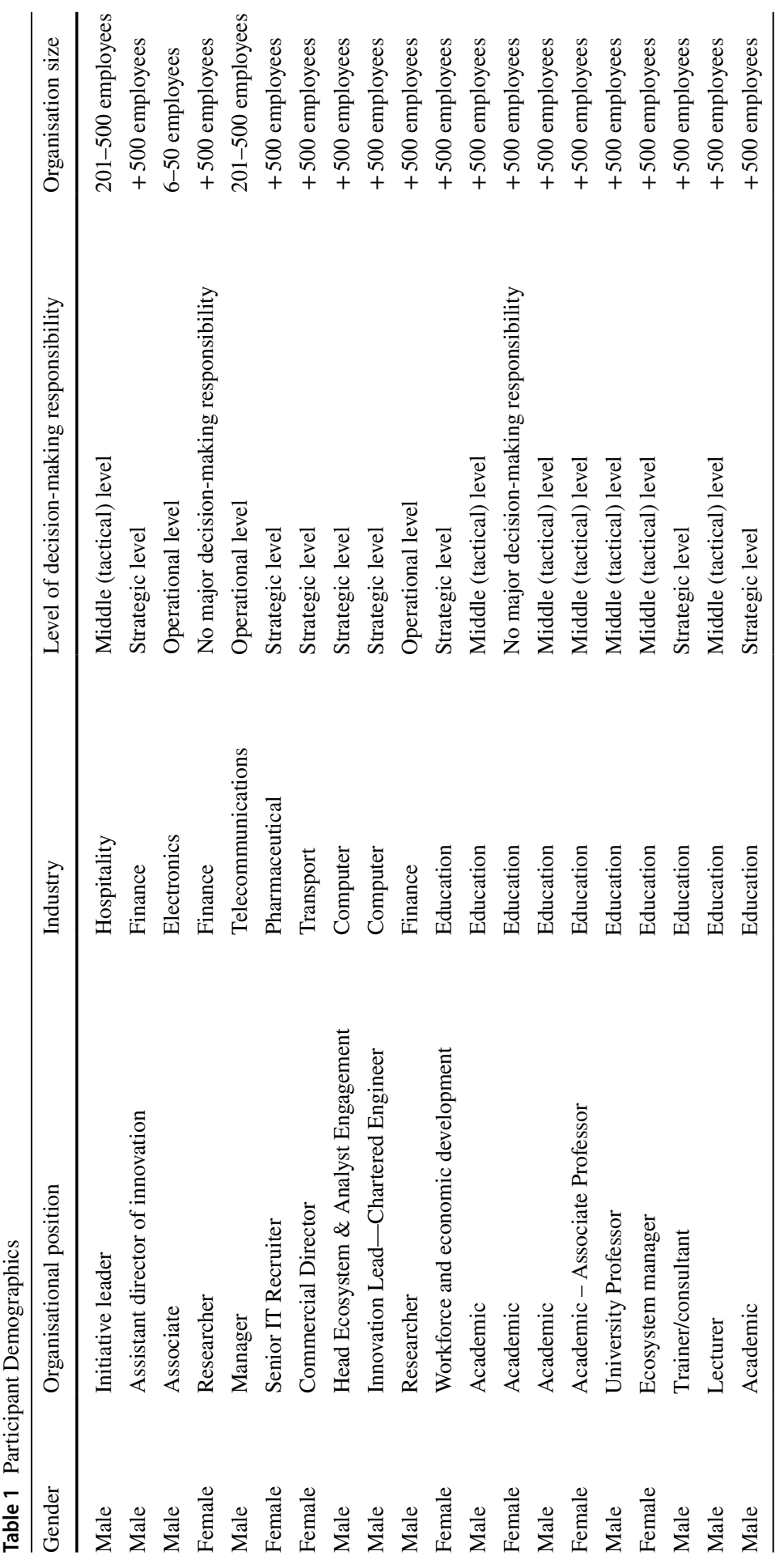


researcher to analyse multiple case studies, which is rarely achieved in traditional case-oriented research (Rihoux and Lobe 2009).

An additional justification for the application of fsQCA within this research is the relatively small number of cases (19) included within the data sample. FsQCA is frequently denoted as being of utmost suitability for small-N analyses (Kraus et al.s 2018a, b), a research situation for which it was originally created (Greckhamer et al. 2008). FsQCA subsequently enables the systematic comparison of a relatively small number of cases through the inclusion of 'logical remainders' (cases without empirical evidence: see Ragin 2006).

Further, the underlying assumption of fsQCA is based upon the notion of setrelations, i.e. whether certain attributes of cases contribute to producing the outcome. As this study aimed to explore the challenges affecting ecosystem management within university-industry ecosystem partnerships, fsQCA enables this to be achieved through employing a set-theoretic research approach that illuminates whether specific challenges are subsets or supersets of ineffective ecosystem management. Finally, according to Berg-Schlosser et al. (2009), one of the original aims of QCA is to develop new theoretical arguments. FsQCA is hence employed in this study to develop new theoretical arguments surrounding the conditions that contribute to ineffective ecosystem management within university-industry partnerships.

The qualitative nature of this study meant that reliability and validity could not be assessed utilising quantitative measures. FsQCA, in being case-oriented in nature, alleviates many of the assumptions of traditional variable-oriented research (Ragin 2006). Indeed, the nature and purpose of fsQCA means that the reliability and validity of latent variables cannot be accounted for, since the technique was originally designed to be used with single item variables (Pappas et al 2019). However, fsQCA does apply the principles of Boolean algebra, where each causal combination is reduced into the simplest logically plausible recipe. This in turn increases replicability (Berg-Schlosser et al. 2009), enabling the researcher to eventually corroborate or falsify results (Rihoux and Lobe 2009).

\subsection{Stages in fsQCA}

The first stage in fsQCA is to calibrate the conditions. FsQCA operates on the basis of set-membership, which is defined through altering the data set such that all values possess a score between 0 and 1 . Thus, the original scale measures required conversion to possess this format, necessitating specification for three threshold values: full membership, full non-membership, and the maximum level of ambiguity. Natural scale breakpoints were utilised to define set-membership, in being an accepted approach to fuzzy-set calibration (Ordanini et al. 2013; Pappas et al. 2016; Woodside 2013), with 6 being outlined as full-membership, 4.5 as a crossover point, and 3 as non-membership. The threshold for non-membership was increased to 3 to account for response bias towards the higher end of the scales. As this study was assessing the extent to which the six conditions contribute to ineffective ecosystem management, the fsQCA analysis was conducted against the absence of the outcome. 
The second stage of fsQCA is to utilise set measures to generate a data matrix known as a truth table. The truth table displays the research data as a list of configurations (Rihoux and Lobe 2009). A truth table possesses $2 \mathrm{k}$ rows, where $\mathrm{k}$ is the number of causal conditions employed within the analysis (Fiss 2011). Each row within the truth table is associated with a specific number of attributes; the truth table lists all logically possible combinations of attributes (Ragin 2006) even if there is no case data that empirically demonstrates a given combination. Having configurations without empirical instances is referred to as limited diversity (Fiss 2011): rows without cases are coined logical remainders.

In the third stage, rows within the truth table are reduced to facilitate the analysis (Fiss 2011). The first step in reducing the rows is to set a benchmark for the minimum number of cases required for a solution to be considered (Fiss 2011). Thus, a specific combination of causal attributes (i.e. one row within the truth table) may be empirically demonstrated by a certain number of cases - therefore the significance of the number of cases needs to be determined so that a threshold can be established. Within small-n analyses such as this, frequency thresholds can be set at 1 . Next, the consistency of each solution needs to be assessed. Consistency refers to the degree to which solution terms and the solution as a whole are subsets of the outcome, with the minimum consistency threshold for any data set recommended as 0.75 (Ragin 2006). Cases with frequency values of less than 1 and consistency values of less than 0.75 were hence removed from the analysis. At the end of stage two, the list of rows should be reduced, to facilitate the final stage of the analysis.

Analysis of the truth table involves the examination of case distribution across the property space, and a systematic identification of those causal conditions sufficient for the outcome of interest to occur (Greckhamer et al. 2008). The analysis involves discovering combinations of conditions that are subsets or supersets of the outcome, thus arriving at sufficient or necessary conditions (Schneider and Wagemann 2012). FsQCA applies the principles of Boolean algebra to combine specific attributes into causal combinations. The combination of causal conditions will result in three solutions being produced for each analysis. Ragin (2006) summarises the three solutions. The first is a 'complex' solution, where no logical remainders (rows without cases) have been included. The second is a parsimonious solution, where logical remainders may be used, without any consideration of their empirical possibility. The final solution is the intermediate, which supposedly bridges the two: the intermediate solution only considers logical remainders that are plausible, where plausibility is judged using the researcher's relevant theoretical and empirical knowledge. For this study, the parsimonious and intermediate solutions are displayed in order to deduce the core and peripheral conditions, in line with Fiss (2011).

\section{Results}

An initial background study was conducted to identify the main challenges pervading university-industry partnerships. Following thematic analyses of these interviews, six key challenges were identified: organisational distance, reluctance to 
Table 2 fsQCA Results

\begin{tabular}{|c|c|c|c|c|c|}
\hline \multirow[b]{2}{*}{ Configuration } & \multicolumn{5}{|c|}{ Solutions } \\
\hline & 1 & 2 & 3 & 4 & 5 \\
\hline Mistrust & $\otimes$ & $\otimes$ & $\bullet$ & $\bullet$ & - \\
\hline Relational risk & • & $\otimes$ & $\otimes$ & $\otimes$ & 0 \\
\hline Relationship disorientation & $\otimes$ & $\otimes$ & $\bullet$ & - & - \\
\hline Organisational distance & $\otimes$ & $\otimes$ & $\otimes$ & - & 0 \\
\hline Miscommunication & $\otimes$ & $\otimes$ & - & $\bullet$ & - \\
\hline Reluctance to innovate & $\otimes$ & $\bullet$ & $\otimes$ & $\otimes$ & $\bullet$ \\
\hline Raw coverage & 0.16666 & 0.14166 & 0.27777 & 0.60138 & 0.225 \\
\hline Unique coverage & 0.06388 & 0.01805 & 0.03472 & 0.35972 & 0.02083 \\
\hline Consistency & 0.96 & 0.76119 & 0.97561 & 0.91737 & 0.75701 \\
\hline Overall solution coverage & & & 0.802778 & & \\
\hline Overall solution consistency & & & 0.821023 & & \\
\hline
\end{tabular}

Note Black circles $(\mathbf{})$ indicate the presence of a condition; crossed out circles $(\otimes)$ indicate the absence of a condition. Large circles represent core conditions; small circles represent peripheral conditions; blank spaces indicate redundant conditions

innovate, relationship disorientation, mistrust, miscommunication, and relational risk. Further details regarding the background study have been excluded from this paper due to space limitations.

For fsQCA, five solutions are displayed for ineffective ecosystem management (Table 2). Solution 1 combines the absence of Mistrust, Relationship Disorientation, Organisational Distance, Miscommunication, and Reluctance to innovate, with the presence of Risk.

All conditions within this solution are peripheral: as they are only present within the intermediate solution, peripheral conditions are deemed to be less important, exchangeable, and expendable, and hence exhibiting a weaker relationship with the outcome (Fiss 2011). In practice, this can be better understood through examining which conditions are core. Solution 2 exhibits the same conditions as Solution 1, but instead Risk manifests as absent, and Reluctance to Innovate manifests as present. The absence of risk leads to the core causal configuration $\sim$ Commfz* $\sim$ Riskfz. As this causal configuration is core, the other conditions within this solution (Mistrust, Relationship Disorientation, Organisational Distance, and Reluctance to Innovate) are peripheral, in being equally effective, whereas Miscommunication and Risk as core conditions are deemed more effective and have greater depth and significance (Fiss 2011). In other words, coreness means effectiveness: in understanding the role of core conditions in a typology, Fiss (2011) argues that examining conditions in terms of the causal role they play within the configuration in order to produce an outcome, core elements are those that are the most important for an outcome to occur. Hence, the remainder of the solutions can be understood in these terms. We direct readers to Ragin (2006) and Fiss (2011) for greater detail on interpreting fsQCA findings. Solution 3 combines the presence of Mistrust, Relationship Disorientation, and Miscommunication, the absence of Risk, Organisational Distance, and 
Reluctance to Innovate. Solution 4 exhibits the same conditions but differs on the presence of Organisational Distance in Solution 4. Finally, Solution 5 combines the presence of all conditions, with the core causal configuration Riskfz*Diffz.

No condition is present across all solutions, inferring that it is unlikely for any condition to retain necessity (Dul 2016): analyses of necessity confirmed this assumption. Overall solution coverage is high at 0.80 , indicating that the five solutions account for a substantial proportion of the outcome. Overall solution consistency is high at 0.82: while a perfect consistency score of 1 has not been achieved, this score does infer that the solutions represent a relatively consistent subset of the outcome.

\section{Discussion}

The solutions can be grouped into three categories. The first category (Solutions 1 and 2) displays all conditions aside from Risk as absent, differing on the presence of Risk and absence of Reluctance to Innovate in Solution 1, compared to the absence of Risk and presence of Reluctance to Innovate in Solution 2. It may perhaps be the case that the presence of Innovation resulted in the core causal configuration $\sim$ Commfz* Riskfz in Solution 2 . As summarised by one participant when discussing their perceptions of risk, "the presence of human beings with differing goals, perceptions of how best to proceed and the difficulties in maintaining clear and transparent communication inherently create weak points where disagreements or misunderstandings rise to the point that they threaten the work itself" (Participant Number 3). However, with effective communication, risk is absent. According to early research by Adner (2006), entrepreneurs must be able to navigate risk when entering an ecosystem, otherwise, such risks present a multitude of further challenges. With R\&D activities purporting inherently risky activities (Radziwon and Bogers 2019) the risks are argued to be higher in university-industry partnerships (Perkmann et al. 2011). Most critical to the success of university-industry collaboration is relational risk, which includes opportunistic behaviour, a lack of commitment to the partnership, and potential spill overs (Fulop and Couchman 2006). Risks faced by universities are potentially more damaging in nature and are more difficult to manage (Fulop and Couchman 2006). FsQCA results hence confirm Perkmann, Neely and Walsh's (2011) findings that unclear objectives are likely to incur further risk: hence, effective communication between partners is likely to mitigate that risk to an extent, explicating the causal configuration within Solution 2. Relationship disorientation and mistrust manifest as absent within this category alone, suggesting that a greater degree of orientation and trust was observed within these partnerships: as professed by one participant, "without trust the partnership will breakdown. Trust needs to be in place to make sure the relationship is stable and to act as a safeguard" (Participant Number 12). Hence, a greater degree of relationship orientation and trust can be observed in this category, providing potential explanations for the absence of risk.

The second category (Solutions 3 and 4) displays the presence of Mistrust, Relationship Disorientation, and Miscommunication. With risk and innovation both 
manifesting as absent, participants expressed that "innovation carries risks and risks create so many more opportunities. Working for a large institution there is always a requirement to lower risks and just do the easiest option” (Participant Number 9). These risks were further affected by the early emergence of these relationships. With Mistrust manifesting as present, participants stated that "Trust takes time to build in the sector and much of the business conducted is with longstanding colleagues" (Participant Number 14): this, alongside the presence of Relationship Disorientation, led to participants expressing that "if [the partner is] just in it for the short run, then it is very transactional and not relational" (Participant Number 12). These partnerships may represent new relationships that have just emerged within the ecosystem: participants expressed that "trust takes time to build and much of [our] business conducted is with longstanding partners" (Participant Number 5). FsQCA findings hence align with previous studies that trust is based upon established, longstanding relationships (Fang et al. 2013; Narteh, 2008; Panteli and Sockalingam, 2005). Trust is assumed to facilitate the relationship between university-industry partners (Valentín 2000) increasing knowledge transfer and reducing the negative effects of partnership differences (Steinmo and Rasmussen 2018). Resource-sharing is more likely to occur within trustworthy partnerships (Tsai 2000). Consequently, a lack of trust can result in misconceptions regarding the utility and application of knowledge (Narteh 2008): as miscommunication is also present in these solutions, it is clear that such misconceptions impacted upon the trust between partners. Hence, mistrust poses a challenge for ecosystem partners, particularly university-industry partnerships due to differences in operational practices and residence within different sectors (Masiello, Izzo and Canoro 2015).

Finally, the third category (Solution 5) interestingly displays the presence of all conditions. With Riskfz*Diffz exhibiting a core causal configuration within this category, the "differing goals" (Participant Number 3) possessed by ecosystem partners were found to incur further risk; participants expressed that "we expect our partner to deliver and sometimes misalignment between ourselves and our partner can be difficult". Hence, organisational differences further resulted in risk in the partnership: "continued nurturing and building of relationships to diminish any distinctions at key levels of the organizations is critical to mitigate any further risk developing" (Participant Number 8). Existing research argues that the common differences in organisational language, culture and goals between industry and academia present a key challenge, affecting inter-organisational learning and knowledge exchange (Steinmo and Rasmussen 2018). Such differences in goals are best managed by improved communication (Plewa et al. 2013) providing support for why miscommunication is present within this solution. In support, Fulop and Couchman (2006) argue that cross-sector collaborations observed within university-industry partnerships results in a clash of cultures, making relational risk more difficult to manage. Moreover, as the presence of risk can emerge due to "new partner dynamics' (Participant Number 11) then "more fundamental relationship foundations mitigate communication issues”. With mistrust present in Solution 5, strong relationship foundations are absent, allowing risk to manifest as a result.

As no condition was necessary for the outcome to occur (i.e. present in all solutions and passing 0.9 thresholds on necessity tests in fsQCA) it can be concluded 
that all conditions are sufficient for the outcome to occur. Each solution constitutes a distinct pathway to the outcome, confirming equifinality and highlighting that ineffective ecosystem management occurs in multiple ways. Each solution displays distinct core and peripheral conditions, confirming that specific causal configurations are more connected with the outcome, with other conditions occupying a less 'significant' relationship. Core conditions across the solutions often manifest in causal configurations, such as $\sim$ Commfz* $\sim$ Riskfz or Riskfz*Diffz, reinforcing the configurational nature of the conditions for leading to ineffective ecosystem management.

\section{Conclusions}

This study has provided empirical insights into the challenges pervading universityindustry partnerships across entrepreneurial ecosystems. In order to examine these challenges, a questionnaire was distributed to ecosystem members to ascertain their perceptions of the challenges and their impact upon ecosystem management. Through the analytical technique of fsQCA, five solutions were revealed, indicating that configurations of conditions contribute to ineffective ecosystem management, emphasising the combinatory nature of the challenges. Solutions across the dataset thus provide support for both propositions underlying this study. As there are multiple solutions for ineffective ecosystem management, the principle of equifinality is observed in this research, hence providing support for Proposition 1. The configurational nature of the core conditions, and the absence of any necessary conditions across all solutions, further confirms that no condition retains responsibility for ineffective ecosystem management (Proposition 2). Ultimately, it can be inferred from the findings that the challenges retain inherent complexities, exerting multiple and distinct effects upon the management of the ecosystem.

\subsection{Theoretical contributions and implications}

This study offers significant theoretical implications for the field of entrepreneurial ecosystems. With many existing studies adopting a comparative lens (Arruda, Nogueira and Costa 2013; Manolova et al. 2017; Voelker 2012) this study offers a methodological contribution through the application of fsQCA to the analysis of entrepreneurial ecosystems. While the application of fsQCA within ecosystems research has risen in recent years (Bacon et al. 2019a, b; Xie and Wang 2020) its usage for analysing challenges of university-industry partnerships across entrepreneurial ecosystems remains a key contribution of this research.

Moreover, while existing studies have examined the role of the university in an ecosystem context (Brito 2018; Meng et al. 2019; Miller et al. 2016; Lakitan 2013) limited research has explored the challenges pervading these relationships, and how they are overcome (Al-Tabbaa and Ankrah 2016). Existing research has examined the barriers to university-industry collaboration (Bruneel et al. 2010) but not specifically in the context of entrepreneurial ecosystems. This study hence extends existing 
debates of Bosco et al. (2018) through examining the challenges of the relationships between industry and academia within entrepreneurial ecosystems.

In identifying these challenges, fsQCA findings exhibited multiple, mutually exclusive pathways to ineffective ecosystem management. Despite some conditions retaining higher causal essentiality with the outcome, and hence requiring greater discussion, no condition exhibited necessity. Thus, it can be inferred that all conditions are sufficient, but not necessary, for ineffective ecosystem management. This study hence contributes to the existing ecosystems literature by providing potential explanations for high failure rates of ecosystem partnerships (Lauritzen and Karafyllia 2019). Moreover, extant studies highlight the interrelations between some challenges, such as trust and relational risk (Fulop and Couchman 2006) miscommunication and organisational distance (Wit-de Vris et al. 2019) and relationship disorientation and miscommunication (Steinmo and Rasmussen 2018), evidencing their mediating influences. While these studies suggest a likely configurational aspect to these challenges, this study confirms these associations, and others, through evidencing the configurational nature of all challenges.

\subsection{Practical contributions and implications}

Alongside theoretical contributions, this study offers important implications for practitioners engaging in university-industry collaboration within an ecosystem context. The configurational nature of the conditions confirms their influence upon one another, indicating that in circumstances where ecosystems are managed ineffectively, it is difficult to pinpoint exactly where the barriers lie. However, what can be ascertained is that, according to the core conditions, in terms of relational risk, it is either miscommunication or organisational distance inducing an effect. Cheng and Fu (2013) argue that well-defined collaborative relationships should be established when initiating an ecosystem partnership: through. strengthening collaborative relationships, relational risk can be eliminated. With miscommunication presenting a key challenge, Sjödin (2019) endorses the usage of advanced ICT and group meetings with partners to increase the clarity and richness of communication within an ecosystem. Finally, with organisational distance incurring a greater likelihood of risk, organisations could consider creating events or workshops that would convey their own normative practices and operational mechanisms to potential ecosystem partners. Not only would this serve to diminish the degree of organisational distance between ecosystem partners, it could also potentially generate new partnerships within the ecosystem of connections. Increasing practitioner awareness of how to eliminate strategies is a critical starting point for eradicating key ecosystem challenges. Practitioners should hence be mindful of these influences and create further awareness of the fact that university-industry collaboration can impact upon the management of the ecosystem as a whole. 


\subsection{Limitations and future research}

As with all empirical studies, a number of limitations pervade this research. Firstly, the sample size of this study is relatively small. While fsQCA possesses particular aptitude for small-n analyses, and the nature of the analysis mitigates the small sample size through the inclusion of logical remainders (see Ragin 2006), the authors still acknowledge that the sample size remains limited. Future studies could conduct similar analyses using a larger sample size. Secondly, as an exploratory study, this paper serves as an initial starting point for examining the challenges pervading university-industry partnerships in ecosystem contexts. Whilst grounded in empirical and theoretical evidence, only six challenges have been explored in this study; future analyses could ascertain whether additional challenges affect these partnership types, indeed achieved through conducting larger scale analyses to obtain a broader range of perspectives.

Additionally, the usage of fsQCA in this manuscript contributes to rising applications of this analytical technique in innovation-related disciplines (Kraus et al. 2018a, b). Despite recent applications of fsQCA to ecosystems research (Bacon et al. 2019a, b; Xie and Wang 2020) this paper offers a distinct contribution in utilising configurational analyses to explore ecosystem challenges pervading universityindustry partnerships. Future research could also contribute to the rise of configurational techniques such as fsQCA, utilising configurational analyses to identify how constellations of conditions lead. to ecosystem-related outcomes.

Finally, this study examines stakeholders' general perceptions of ecosystem challenges, without focusing on a specific ecosystem context. As such, future studies could investigate university-industry partnerships on more specific ecosystem types. Relatedly, as participants were obtained from different entrepreneurial ecosystems, albeit all UK-based, the vital role of geographical contexts within these ecosystems remains largely absent from this research. The authors again acknowledge that these regional influences did not arise as a barrier (nor, indeed, an inhibitor) for effective ecosystem management within the data collection process: nonetheless, ascertaining whether these challenges are apparent in regional entrepreneurial ecosystems, achieved through case-study analyses, comprises a fruitful avenue for further research.

\section{Appendix A-Questionnaire items}

Please indicate how much you agree or disagree with the following statements: (1 - totally disagree, 7 - totally agree).

\section{Trust}

To what extent do you agree/disagree that a lack of trust presents a challenge to ecosystem management?

Please provide an explanation for your response. 


\section{Relational Risk}

To what extent do you agree/disagree that ecosystem partnerships present risks that affect ecosystem management?

Please provide an explanation for your response.

\section{Relationship disorientation}

To what extent do you agree/disagree that reluctance to engage in partnerships presents a challenge to ecosystem management?

Please provide an explanation for your response.

\section{Organisational distance}

To what extent do you agree/disagree that organisational differences between partners present a challenge to ecosystem management?

Please provide an explanation for your response.

\section{Miscommunication}

To what extent do you agree/disagree that miscommunication between partners presents a challenge to ecosystem management?

Please provide an explanation for your response.

\section{Reluctance to innovate}

To what extent do you agree/disagree that a reluctance to innovate presents a challenge to ecosystem management?

Please provide an explanation for your response.

\section{Ecosystem management}

Our ecosystem is effective in managing strategic contributions.

Our ecosystem is invested in by all members.

Our ecosystem evolves based on creating end-to-end experiences of customer value.

We implement community-level governance to our ecosystem.

Our ecosystem is aligned around shared intentions and a shared vision of the ecosystem future. 
Author contributions All authors contributed to the study conception and design. Material preparation, data collection and analysis were performed by Dr ECB and Professor MDW. The first draft of the manuscript was written by Dr ECB and both authors commented on previous versions of the manuscript. Both authors read and approved the final manuscript.

Data availability Confidentiality was promised to participants, and hence complete raw data extracts are omitted from the article.

\section{Compliance with ethical standards}

Conflict of interest The authors declare that they have no conflict of interest.

Open Access This article is licensed under a Creative Commons Attribution 4.0 International License, which permits use, sharing, adaptation, distribution and reproduction in any medium or format, as long as you give appropriate credit to the original author(s) and the source, provide a link to the Creative Commons licence, and indicate if changes were made. The images or other third party material in this article are included in the article's Creative Commons licence, unless indicated otherwise in a credit line to the material. If material is not included in the article's Creative Commons licence and your intended use is not permitted by statutory regulation or exceeds the permitted use, you will need to obtain permission directly from the copyright holder. To view a copy of this licence, visit http://creativecommons.org/licen ses/by/4.0/.

\section{References}

Acs Z, Stam E, Audretsch D, O'Connor A (2017) The lineages of the entrepreneurial ecosystem approach. Small Bus Econ 49:1-10. https://doi.org/10.1007/s11187-017-9864-8

Adner R (2006) Match your innovation strategy to your innovation ecosystem. Harv Bus Rev 84:1-11

Al-Tabbaa O, Ankrah S (2016) Social capital to facilitate 'engineered' university-industry collaboration for technology transfer: A dynamic perspective. Technol Forecast Soc Change 104:1-15. https://doi. org/10.1016/j.techfore.2015.11.027

Arant W, Fornahl D, Grashof N, Hesse K, Söllner C (2019) University-industry collaborations-The key to radical innovations? Rev Regional Res 39:119-141. https://doi.org/10.1007/s10037-019-00133-3

Arruda C, Nogueira V, Cozzi A, Costa V (2014) The Brazilian Entrepreneurial Ecosystem of Startups: An Analysis of Entrepreneurship Determinants in Brazil and the Perceptions Around the Brazilian Regulatory Framework. Entrepreneurship in BRICS. https://doi.org/10.1007/978-3-319-11412-5_2

Audretsch D, Belitski M (2016) Entrepreneurial ecosystems in cities: establishing the framework conditions. J Technol Transfer 42:1030-1051. https://doi.org/10.1007/s10961-016-9473-8

Autio E, Levie J (2017) Management of entrepreneurial ecosystems. Ahmetoglu G, Chamorro-Premuzic T, Klinger B, Karcisky T. The Wiley handbook of entrepreneurship. Wiley-Blackwell, London, pp 423-449

Autio E, Kenney M, Mustar P, Siegel D, Wright M (2014) Entrepreneurial innovation: The importance of context. Res Policy 43:1097-1108. https://doi.org/10.1016/j.respol.2014.01.015

Autio E, Nambisan S, Thomas L, Wright M (2018) Digital affordances, spatial affordances, and the genesis of entrepreneurial ecosystems. Strateg Entrepreneurship J 12:72-95. https://doi.org/10.1002/ sej. 1266

Bacon E, Williams M, Davies G (2019a) Recipes for success: Conditions for knowledge transfer across open innovation ecosystems. Int J Inf Manag 49:377-387. https://doi.org/10.1016/j.ijinf omgt.2019.07.012

Bacon E, Williams M, Davies G (2019b) Coopetition in innovation ecosystems: A comparative analysis of knowledge transfer configurations. J Bus Res 115:307-316. https://doi.org/10.1016/j.jbusr es.2019.11.005

Berg-Schlosser D, De Meur G, Rihoux B, Ragin C (2009) Qualitative comparative analysis (QCA) as an approach. Rihoux B, Ragin C Configurational comparative methods: Qualitative comparative analysis (QCA) and related techniques SAGE, Thousand Oaks, CA, pp.1-18. 
Boardman C, Gray D (2010) The new science and engineering management: cooperative research centers as government policies, industry strategies, and organizations. J Technol Transfer 35:445-459. https ://doi.org/10.1007/s10961-010-9162-y

Bouncken R, Laudien S, Fredrich V, Görmar L (2018) Coopetition in coworking-spaces: value creation and appropriation tensions in an entrepreneurial space. Rev Manag Sci 12:385-410. https://doi. org/10.1007/s11846-017-0267-7

Breznitz S, Zhang Q (2019) Fostering the growth of student start-ups from university accelerators: an entrepreneurial ecosystem perspective. Indust Corp Change 28:855-873. https://doi.org/10.1093/ icc/dtz033

Brito C (2018) Promoting the creation of Innovation Ecosystems: the case of the University of Porto. J Innov Manag 6:8-16. https://doi.org/10.24840/2183-0606_006-003_0002

Brown R, Mason C (2017) Looking inside the spiky bits: a critical review and conceptualisation of entrepreneurial ecosystems. Small Bus Econ 49:11-30. https://doi.org/10.1007/s11187-017-9865-7

Bruneel J, d'Este P, Salter A (2010) Investigating the factors that diminish the barriers to universityindustry collaboration. Res Pol 39:858-868. https://doi.org/10.1016/j.respol.2010.03.006

Carayannis E, Campbell D (2009) "Mode 3" and "Quadruple Helix": toward a 21st century fractal innovation ecosystem. Int J Tech Manag 46:201. https://doi.org/10.1504/ijtm.2009.023374

Carayannis E, Grigoroudis E, Stamati D, Valvi T (2019) Social business model innovation: A quadruple/ quintuple helix-based social innovation ecosystem. IEEE Trans Eng Manag. https://doi.org/10.1109/ TEM.2019.2914408

Cavallo A, Ghezzi A, Balocco R (2018) Entrepreneurial ecosystem research: present debates and future directions. Int Entrepreneurship Manag J 15:1291-1321. https://doi.org/10.1007/s11365-018-0526-3

Cheng J, Fu Y (2013) Inter-organizational relationships and knowledge sharing through the relationship and institutional orientations in supply chains. Int J Inf Manag 33:473-484. https://doi. org/10.1016/j.ijinfomgt.2013.01.002

Chesbrough H, Vanhaverbeke W, West J (eds) (2006) Open innovation: Researching a new paradigm. Oxford University Press on Demand, Oxford

de Vasconcelos GL, Facin A, Salerno M, Ikenami R (2018) Unpacking the innovation ecosystem construct: Evolution, gaps and trends. Technol Forecast Soc Change 136:30-48. https://doi. org/10.1016/j.techfore.2016.11.009

de Wit-de VE, Dolfsma W, van der Windt H, Gerkema M (2019) Knowledge transfer in university-industry research partnerships: a review. J Technol Transfer 44:1236-1255. https://doi. org/10.1007/s10961-018-9660-X

Del Bosco B, Chierici R, Mazzucchelli A (2018) Fostering entrepreneurship: an innovative business model to link innovation and new venture creation. Rev Manag Sci 13:561-574. https://doi. org/10.1007/s11846-018-0318-8

Dul J (2016) Identifying single necessary conditions with NCA and fsQCA. J Bus Res 69:1516-1523. https://doi.org/10.1016/j.jbusres.2015.10.134

Erina I, Shatrevich V, Gaile-Sarkane E (2017) Impact of stakeholder groups on development of a regional entrepreneurial ecosystem. Eur Plan Stud 25:755-771. https://doi.org/10.1080/09654 313.2017.1282077

Fang S, Yang C, Hsu W (2013) Inter-organizational knowledge transfer: the perspective of knowledge governance. J Knowl Manag 17:943-957. https://doi.org/10.1108/jkm-04-2013-0138

Ferreira J, Carayannis E (2019) University-industry knowledge transfer-unpacking the "black box": an introduction. Knowl Manag Res Practice 17:353-357. https://doi.org/10.1080/14778 238.2019.1666514

Ferreira J, Fernandes C, Kraus S (2017) Entrepreneurship research: mapping intellectual structures and research trends. Rev Manag Sci 13:181-205. https://doi.org/10.1007/s11846-017-0242-3

Fiss P (2011) Building better causal theories: A fuzzy set approach to typologies in organization research. Acad Manag J 54:393-420. https://doi.org/10.5465/amj.2011.60263120

Fulop L, Couchman P (2006) Facing up to the risks in commercially focused university-industry R\&D partnerships. High Educ Res Dev 25:163-177. https://doi.org/10.1080/072943606006103 96

Greckhamer T, Misangyi V, Elms H, Lacey R (2008) Using qualitative comparative analysis in strategic management research: An examination of combinations of industry, corporate, and businessunit effects. Org Res Methods 11:695-726. https://doi.org/10.1177/1094428107302907 
Hakala H, O'Shea G, Farny S, Luoto S (2019) Re-storying the Business, Innovation and Entrepreneurial Ecosystem Concepts: The Model-Narrative Review Method. Int J Manage Rev 22:10-32. https://doi.org/10.1111/ijmr.12212

Hayter C (2016) A trajectory of early-stage spinoff success: the role of knowledge intermediaries within an entrepreneurial university ecosystem. Small Bus Econ 47:33-656. https://doi. org/10.1007/s11187-016-9756-3

Hekkert M, Suurs R, Negro S, Kuhlmann S, Smits R (2007) Functions of innovation systems: A new approach for analysing technological change. Technol Forecast Soc Change 74:413-432. https:// doi.org/10.1016/j.techfore.2006.03.002

Howells J, Ramlogan R, Cheng S (2012) Universities in an open innovation system: a UK perspective. Int J Entrepreneurial Behav Res 18:440-456. https://doi.org/10.1108/13552551211239483

Ivascu L, Cirjaliu B, Draghici A (2016) Business model for the university-industry collaboration in open innovation. Proc Econ Financ 39:674-678. https://doi.org/10.1016/s2212-5671(16)30288-x

Kang Q, Li H, Cheng Y, Kraus S (2019) Entrepreneurial ecosystems: analysing the status quo. Knowl Manag Res \& Practice. https://doi.org/10.1080/14778238.2019.1701964

Kraus S, Meier F, Niemand T, Bouncken R, Ritala P (2018a) In search for the ideal coopetition partner: an experimental study. Rev Manag Sci 12:1025-1053. https://doi.org/10.1007/s1184 6-017-0237-0

Kraus S, Ribeiro-Soriano D, Schüssler M (2018b) Fuzzy-set qualitative comparative analysis (fsQCA) in entrepreneurship and innovation research-the rise of a method. Int Entrepreneurship Manage J 14:15-33. https://doi.org/10.1007/s11365-017-0461-8

Lahikainen K, Kolhinen J, Ruskovaara E, Pihkala T (2019) Challenges to the development of an entrepreneurial university ecosystem: The case of a Finnish university campus. Industry Higher Ed 33:96107. https://doi.org/10.1177/0950422218815806

Lakitan B (2013) Connecting all the dots: Identifying the "actor level" challenges inestablishing effective innovation system in Indonesia. Techno Soc 35:41-54. https://doi.org/10.1016/j.techs oc. 2013.03 .002

Lauritzen G, Karafyllia M (2019) Perspective: leveraging open innovation through paradox. J Product Innovation Manage 36:107-121. https://doi.org/10.1111/jpim.1247

Laursen K, Salter A (2004) Searching high and low: what types of firms use universities as a source of innovation? Res Policy 33:1201-1215. https://doi.org/10.1016/j.respol.2004.07.004

Liguori E, Bendickson J, Solomon S, McDowell W (2019) Development of a multi-dimensional measure for assessing entrepreneurial ecosystems. Entrepreneurship Regional Dev 31:7-21. https://doi. org/10.1080/08985626.2018.1537144

Lubik S, Garnsey E, Minshall T (2013) Evolving toward an ecosystem perspective: market strategies for science-based ventures. Paper presented at the $35^{\text {th }}$ DRUID Society Conference 2013, CBS, Barcelona, Spain.

Malecki E (2018) Entrepreneurship and entrepreneurial ecosystems. Geogr. Compass 12:e12359. https:// doi.org/10.1111/gec3.12359

Manolova T, Brush C, Edelman L, Robb A, Welter F (2017) Entrepreneurial ecosystems and growth of women's entrepreneurship. Edward Elgar Publishing, Cheltenham

Masiello B, Izzo F, Canoro C (2015) The structural, relational and cognitive configuration of innovation networks between SMEs and public research organisations. Int Small Bus J 33:169-193. https://doi. org/10.1177/0266242613485610

Meng D, Li X, Rong K (2019) Industry-to-university knowledge transfer in ecosystem-based academic entrepreneurship: Case study of automotive dynamics \& control group in Tsinghua University. Technol Forecast Soc Change 141:249-262. https://doi.org/10.1016/j.techfore.2018.10.005

Miller D, Acs Z (2017) The campus as entrepreneurial ecosystem: the University of Chicago. Small Bus Econ 49:75-95. https://doi.org/10.1007/s11187-017-9868-4

Miller K, McAdam R, Moffett S et al (2016) Knowledge transfer in university quadruple helix ecosystems: an absorptive capacity perspective. R\&D Manag 46:383-399. https://doi.org/10.1111/ radm. 12182

Moore J (1993) Predators and prey: the new ecology of competition. Harv Bus Rev 71:75-86

Moore J (1996) The death of competition: leadership and strategy in the age of business ecosystems. HarperBusiness, New York

Narteh B (2008) Knowledge transfer in developed-developing country interfirm collaborations: A conceptual framework. J Knowl Manag 12:78-91. https://doi.org/10.1108/13673270810852403 
Nicholls-Nixon C, Valliere D, Gedeon S, Wise S (2020) Entrepreneurial ecosystems and the lifecycle of university business incubators: An integrative case study. Int Entrepreneurship Manag J. https://doi. org/10.1007/s11365-019-00622-4

Nieto M, Santamaría L (2007) The importance of diverse collaborative networks for the novelty of product innovation. Technovation 27:367-377. https://doi.org/10.1016/j.technovation.2006.10.001

Ordanini A, Parasuraman A, Rubera G (2013) When the Recipe Is More Important Than the Ingredients. J Serv Res 17:134-149. https://doi.org/10.1177/1094670513513337

Panteli N, Sockalingam S (2005) Trust and conflict within virtual inter-organizational alliances: a framework for facilitating knowledge sharing. Decis Support Syst 39:599-617. https://doi.org/10.1016/j. dss.2004.03.003

Pappas I, Kourouthanassis P, Giannakos M, Chrissikopoulos V (2016) Explaining online shopping behavior with fsQCA: The role of cognitive and affective perceptions. J Bus Res 69:794-803. https://doi. org/10.1016/j.jbusres.2015.07.010

Pappas I, Giannakos M, Sampson D (2019) Fuzzy set analysis as a means to understand users of 21stcentury learning systems: The case of mobile learning and reflections on learning analytics research. Comput Human Behav 92:646-659. https://doi.org/10.1016/j.chb.2017.10.010

Perkmann M, Walsh K (2007) University-industry relationships and open innovation: Towards a research agenda. Int J Manag Rev 9:259-280. https://doi.org/10.1111/j.1468-2370.2007.00225.x

Perkmann M, Neely A, Walsh K (2011) How should firms evaluate success in university-industry alliances? A performance measurement system. R\&D Manag 41:202-216. https://doi.org/10.111 $1 / \mathrm{j} .1467-9310.2011 .00637 . x$

Plewa C, Korff N, Johnson C, Macpherson G, Baaken T, Rampersad G (2013) The evolution of university-industry linkages-A framework. J Eng Technol Manag 30:21-44. https://doi.org/10.1016/j. jengtecman.2012.11.005

Radziwon A, Bogers M (2019) Open innovation in SMEs: Exploring inter-organizational relationships in an ecosystem. Technol Forecast Soc Change 146:573-587. https://doi.org/10.1016/j.techf ore.2018.04.021

Ragin C (2006) Set Relations in Social Research: Evaluating Their Consistency and Coverage. Polit Anal 14:291-310. https://doi.org/10.1093/pan/mpj019

Rihoux B, Lobe B (2009) The case for qualitative comparative analysis (QCA): Adding leverage for thick cross-case comparison. Byrne D. Ragin C The Sage handbook of case-based method, SAGE, New Delhi, India, pp 222-242

Roig-Tierno N, Kraus S, Cruz S (2018) The relation between coopetition and innovation/entrepreneurship. Rev Manag Sci 12:379-383

Santoro M, Saparito P (2006) Self-interest assumption and relational trust in university-industry knowledge transfers. IEEE T Eng Manag 53:335-347. https://doi.org/10.1109/tem.2006.878103

Schaeffer V, Matt M (2016) Development of academic entrepreneurship in a non-mature context: the role of the university as a hub-organisation. Entrepreneurship Reg Dev 28:724-745. https://doi. org/10.1080/08985626.2016.1247915

Schneider P (2018) Managerial challenges of Industry 4.0: an empirically backed research agenda for a nascent field. Rev Manag Sci 12:803-848. https://doi.org/10.1007/s11846-018-0283-2

Schneider C, Wagemann C (2012) Set-theoretic methods for the social sciences: A guide to qualitative comparative analysis. Cambridge University Press, Cambridge

Sjödin D (2019) Knowledge processing and ecosystem co-creation for process innovation: Managing joint knowledge processing in process innovation projects. Int Entrepreneurship Manag J 15:135162. https://doi.org/10.1007/s11365-018-0550-3

Steinmo M, Rasmussen E (2018) The interplay of cognitive and relational social capital dimensions in university-industry collaboration: Overcoming the experience barrier. Res Policy 47:1964-1974. https://doi.org/10.1016/j.respol.2018.07.004

Theodoraki C, Messeghem K (2017) Exploring the entrepreneurial ecosystem in the field of entrepreneurial support: a multi-level approach. Int J Entrepreneurship Small Bus 31:47. https://doi. org/10.1504/ijesb.2017.10004607

Tsai W (2000) Social capital, strategic relatedness and the formation of intraorganizational linkages. Strateg Manag J 21:925-939

Valentín E (2000) University-industry cooperation: A framework of benefits and obstacles. Ind High Educ 14:165-172. https://doi.org/10.5367/000000000101295011

Voelker T (2012) Entrepreneurial ecosystems: evolutionary paths or differentiated systems. Bus Stud J $4: 43-61$ 
West J (2014). Challenges of funding open innovation platforms. Chesbrough H, Vanhaverbeke W, West J New frontiers in open innovation, Oxford University Press, Oxford, England, pp.22-49.

Woodside A (2013) Moving beyond multiple regression analysis to algorithms: Calling for adoption of a paradigm shift from symmetric to asymmetric thinking in data analysis and crafting theory. $\mathrm{J}$ Bus Res 66:463-472. https://doi.org/10.1016/j.jbusres.2012.12.02

Xie X, Wang H (2020) How can open innovation ecosystem modes push product innovation forward? An fsQCA analysis. J Bus Res 108:29-41. https://doi.org/10.1016/j.jbusres.2019.10.011

Zardini A, Ricciardi F, Bullini Orlandi L, Rossignoli C (2020) eBusiness networks as breeding grounds for entrepreneurial options: organizational implications. Rev Manag Sci 14:1029-1046. https://doi. org/10.1007/s11846-018-0317-9

Publisher's Note Springer Nature remains neutral with regard to jurisdictional claims in published maps and institutional affiliations. 